\title{
Open and transparent sports science research: the role of journals to move the field forward
}

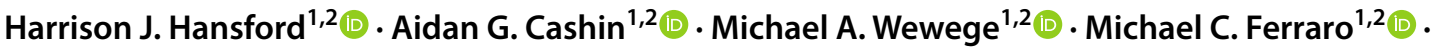 \\ James H. McAuley ${ }^{1,2}\left(\right.$ D . Matthew D. Jones ${ }^{1,2}($ D $\cdot$ the TOP Sport Science Collaborators
}

Received: 16 November 2021 / Accepted: 13 January 2022 / Published online: 29 January 2022

(c) The Author(s) under exclusive licence to European Society of Sports Traumatology, Knee Surgery, Arthroscopy (ESSKA) 2022

Keywords Open science $\cdot$ Transparency $\cdot$ Replicability

\section{Abbreviation}

TOP Transparency and openness promotion

In recent years there has been a 'crisis of confidence' or 'reproducibility crisis' in many areas of science including psychology [1], neuroscience [2] and social science [3]. These issues stand to reduce confidence in the findings of science from those fields, potentially resulting in wasted research funding, resources and effort [4]. The field of sports science is not immune to these issues, with several appeals to improve research quality and move the field forward [5-7]. Research transparency and openness are essential to adequately appraise, replicate, and implement research findings into clinical practice and health policy. Greater transparency and openness in sports science research is needed to increase the confidence in research findings and aid reproducibility.

Sports science journals can support researchers to publish more transparent and open research $[8,9]$ by implementing practices such as requiring pre-registration [10], reporting guidelines [11] and sharing of data and code [12, 13]. Journal policies that actively support transparent and open research practices can improve the quality, reproducibility and replicability of the research they publish [14, 15]. For example, a change to editorial policy in the Nature life-science journals introducing a reporting checklist led to improved reporting of the risk of bias for in vivo research [15]. The Transparency and Openness Promotion (TOP)

Harrison J. Hansford

h.hansford@unsw.edu.au

1 Department of Exercise Physiology, Faculty of Medicine and Health, School of Health Sciences, UNSW Sydney, 61-63 Botany St, Randwick, NSW 2031, Australia

2 Centre for Pain IMPACT, Neuroscience Research Australia, Sydney, Australia
Guidelines [16] provide an excellent overview of the key areas and practices journals should support to improve research transparency and openness.

To illustrate this issue, we appraised how well the policies of the leading 38 sports science journals support transparent and open research practices. These journals were evaluated using the TOP Factor (https://osf.io/t2yu5/)—a metric for evaluating the degree to which journal policies promote transparency and openness [17]. The TOP Factor is calculated as the sum of journal implementation of the eight modular standards within the TOP Guidelines and an additional standard related to the publication of replication studies. Knee Surgery Sports Traumatology Arthroscopy's TOP Factor scores are provided in Fig. 1, alongside summary data from the top 38 sport science journals.

The mean TOP Factor score for the 38 leading sports science journals was $2.05 \pm 1.99 / 27$ showing a low level of engagement with transparency and openness standards. Compared to other sports science journals, Knee Surgery Sports Traumatology Arthroscopy showed greater engagement with transparency and openness standards with a total TOP Factor score of $7 / 27$. The low TOP Factor scores seen across sports science journals highlight an important opportunity for journals to update their policies towards increased engagement with transparent and open practices to ultimately move the field forward.

There are several key areas where sports science journals can improve the transparency and openness of the research they publish. Sports science journals, including Knee Surgery Sports Traumatology Arthroscopy, scored poorly (median score 0/3) for TOP Factor items "data citation", "code citation", "data transparency", "code transparency", "research material transparency", "analysis preregistration" and "replication" (Fig. 1). We encourage sports science journals to review their journal policies to better support these practices and help improve the quality and transparency of 

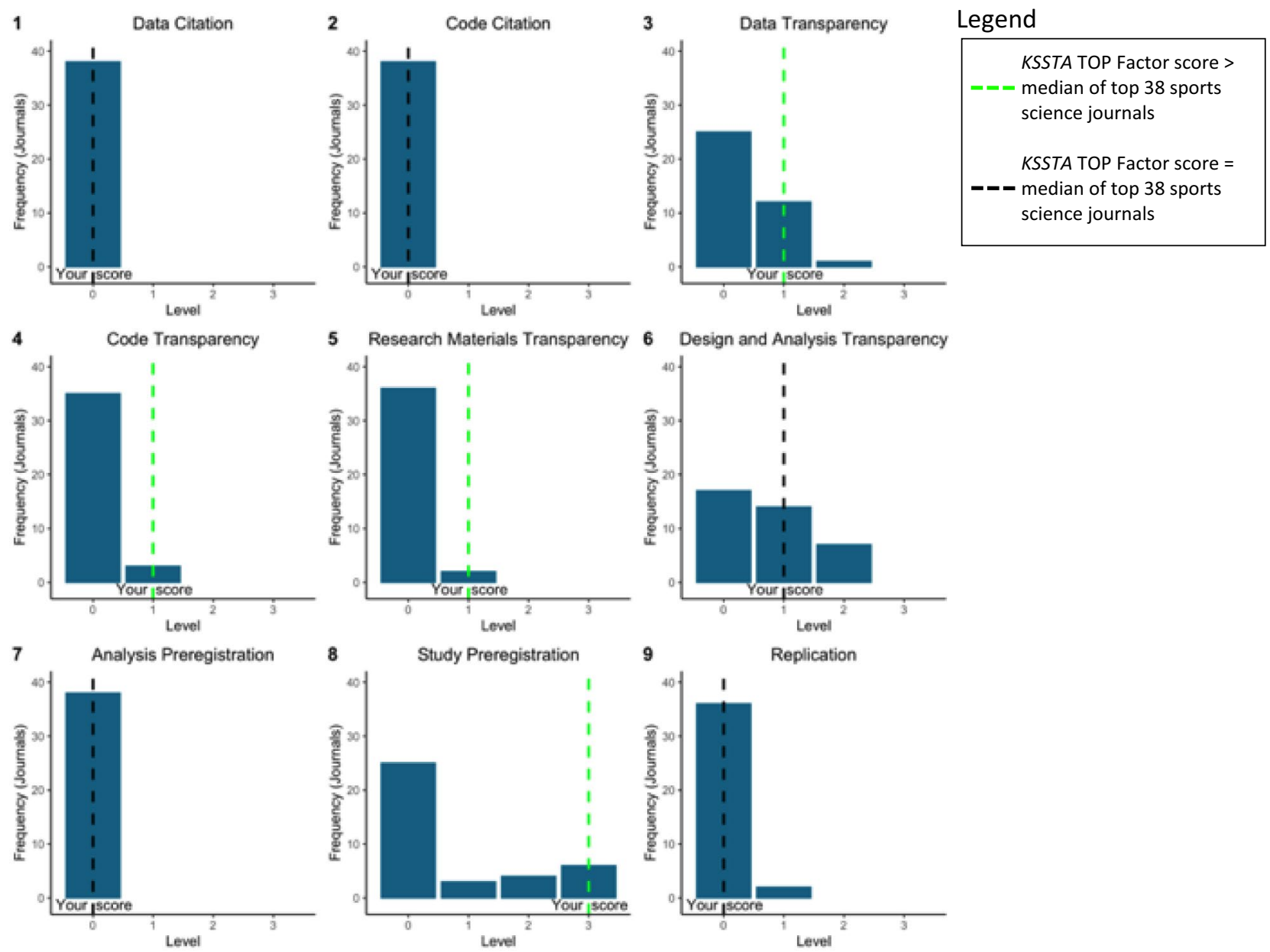

Fig. 1 A panel of histograms detailing the 38 top sports science journals scores for each item of the TOP Factor. The dotted line indicates Knee Surgery Sports Traumatology Arthroscopy's (KSSTA) score for each item, with the colour of the line indicating the position relative to the median score of the top 38 sports science journals. Black indicates the score of KSSTA was equal to the median, and green indicates the score of KSSTA was above the median (better). For TOP items $1-8$, a score of: $0=$ not mentioned or 'encouraged' by the journal policy, $1=$ recommended by the journal policy, $2=$ required by the journal policy, $3=$ required and enforced by the journal policy. For item 9 , a score of: $0=$ not mentioned by the journal policy, $1=$ journal states significance or novelty are not criteria for publication, $2=$ journal reviews replication studies blinded to results, $3=$ journal accepts registered reports sports science research. For example, research material, code and data transparency are important for improving the ability to synthesise, verify and replicate research. Platforms such as the Open Science Framework (osf.io) [18], FigShare (figshare.com) [19] and Dryad (datadryad.org) [20] enable public sharing of research material, code and data; doing so may also increase trust in study findings [16].

"Study preregistration" was the only TOP Factor item on which some journals achieved a maximum (best) score. Knee Surgery Sports Traumatology Arthroscopy was one of these journals. Study preregistration is an important step in reducing the risk of selective reporting and outcome switching which can bias study findings, distort the evidence-base, and potentially lead to harm for patients [21-23]. Preregistration requires authors to prospectively specify the research objectives, design, and methods before data is collected or becomes available. Critically, preregistration makes clearer the distinction between confirmatory research that is important for hypotheses testing, and unplanned, exploratory research that is important for generating hypotheses [10]. Specific, precise and exhaustive preregistration of research [24], along with transparent reporting of any deviations, allows peer reviewers and research end users to better assess the credibility of the research findings.

There is great opportunity among the top sports science journals to improve engagement with research transparency and openness. Knee Surgery Sports Traumatology Arthroscopy had one of the highest TOP Factor scores among the other top sports science journals and can further champion transparent and open research practices by requiring the 
sharing of data and code (transparency), and requiring both study and analysis preregistration. Journals are key stakeholders in the publication of high-quality and reproducible research and can support transparent and open research practices by updating their policies. The Centre for Open Science (https://cos.io/top/) provides advice and resources to help guide this. Greater transparency and openness will improve the conduct and translation of sport science research to ultimately move the field forward.

Author contributions MDJ conceived the study. HJH drafted the initial manuscript, HJH, AGC, MAW, MCF, MDJ conducted data extraction. JHM provided expert input. All authors contributed meaningfully to the style and content of the final manuscript.

Funding Michael Wewege was supported by a Postgraduate Scholarship from the National Health and Medical Research Council of Australia, a School of Medical Sciences Top-Up Scholarship from the University of New South Wales, and a PhD Top-Up Scholarship from Neuroscience Research Australia. Michael Ferraro was supported by an Australian government research training programme scholarship, and a PhD Top-Up Scholarship from Neuroscience Research Australia. All other authors have no sources of funding to declare.

Availability of data and material All data and code are available on OSF (https://osf.io/d2t4s/).

\section{Declarations}

Conflict of interest All authors declare they have no conflicts of interest.

Ethical approval No ethical approval was necessary.

\section{References}

1. Open Science Collaboration (2015) Estimating the reproducibility of psychological science. Science 349:4716

2. Button KS, Ioannidis JP, Mokrysz C, Nosek BA, Flint J, Robinson ES et al (2013) Power failure: why small sample size undermines the reliability of neuroscience. Nat Rev Neurosci 14:365-376

3. Camerer CF, Dreber A, Holzmeister F, Ho T-H, Huber J, Johannesson $\mathrm{M}$ et al (2018) Evaluating the replicability of social science experiments in Nature and Science between 2010 and 2015. Nat Hum Behav 2:637-644

4. Ioannidis JPA (2005) Why most published research findings are false. PLoS Med 2:e124

5. Bernards JR, Sato K, Haff GG, Bazyler CD (2017) Current research and statistical practices in sport science and a need for change. Sports 5:87

6. Caldwell AR, Vigotsky AD, Tenan MS, Radel R, Mellor DT, Kreutzer A et al (2020) Moving sport and exercise science forward: a call for the adoption of more transparent research practices. Sports Med 50:449-459
7. Halperin I, Vigotsky AD, Foster C, Pyne DB (2018) Strengthening the practice of exercise and sport-science research. Int J Sports Physiol Perform 13:127-134

8. Ioannidis JP (2015) How to make more published research true. Revista Cubana de Información en Ciencias de la Salud (ACIMED) 26:187-200

9. Munafò MR, Nosek BA, Bishop DVM, Button KS, Chambers CD, Percie du Sert N et al (2017) A manifesto for reproducible science. Nat Hum Behav 1:0021

10. Nosek BA, Ebersole CR, DeHaven AC, Mellor DT (2018) The preregistration revolution. Proc Natl Acad Sci USA 115:2600-2606

11. Simera I, Moher D, Hirst A, Hoey J, Schulz KF, Altman DG (2010) Transparent and accurate reporting increases reliability, utility, and impact of your research: reporting guidelines and the EQUATOR Network. BMC Med 8:1-6

12. Herbert R, Elkins M (2017) Publishing code: an initiative to enhance transparency of data analyses reported in Journal of Physiotherapy. J Physiother 63:129-130

13. Naudet F, Sakarovitch C, Janiaud P, Cristea I, Fanelli D, Moher D et al (2018) Data sharing and reanalysis of randomized controlled trials in leading biomedical journals with a full data sharing policy: survey of studies published in The BMJ and PLOS Medicine. BMJ 360:400

14. Cashin AG, Bagg MK, Richards GC, Toomey E, McAuley JH, Lee $H$ (2020) Limited engagement with transparent and open science standards in the policies of pain journals: a cross-sectional evaluation. BMJ Evid Based Med 26:313-319

15. The NPQIP Collaborative Group (2019) Did a change in Nature journals' editorial policy for life sciences research improve reporting? BMJ Open Sci 3:00035

16. Nosek BA, Alter G, Banks GC, Borsboom D, Bowman SD, Breckler SJ et al (2015) Promoting an open research culture. Science 348:1422-1425

17. Mayo-Wilson E, Grant S, Supplee L, Kianersi S, Amin A, DeHaven A et al (2021) Evaluating implementation of the Transparency and Openness Promotion (TOP) guidelines: the TRUST process for rating journal policies, procedures, and practices. Res Integr Peer Rev 6:9

18. Foster ED, Deardorff A (2017) Open Science Framework (OSF). J Med Libr Assoc JMLA 105:203-206

19. Hahnel M. Figshare. 2012; https://figshare.com/. Accessed 2021.

20. Greenberg J, White HC, Carrier S, Scherle R (2009) A metadata best practice for a scientific data repository. J Libr Metadata 9:194-212

21. Chan A-W, Song F, Vickers A, Jefferson T, Dickersin K, Gøtzsche $P C$ et al (2014) Increasing value and reducing waste: addressing inaccessible research. Lancet 383:257-266

22. Hart B, Lundh A, Bero L (2012) Effect of reporting bias on meta-analyses of drug trials: reanalysis of meta-analyses. BMJ 344:7202

23. Kirkham JJ, Dwan KM, Altman DG, Gamble C, Dodd S, Smyth R et al (2010) The impact of outcome reporting bias in randomised controlled trials on a cohort of systematic reviews. BMJ 340:365

24. Wicherts JM, Veldkamp CL, Augusteijn HE, Bakker M, Van Aert R, Van Assen MA (2016) Degrees of freedom in planning, running, analyzing, and reporting psychological studies: a checklist to avoid p-hacking. Front Psychol 7:1832

Publisher's Note Springer Nature remains neutral with regard to jurisdictional claims in published maps and institutional affiliations. 